\title{
FORMAÇÃO INICIAL E CURRÍCULO NO CEFD/UFES*
}

\author{
Fernanda Simone Lopes de Paiva ${ }^{* *}$ \\ Nelson Figueiredo Andrade Filho** \\ Zenólia Cristina Campos Figueiredo**
}

\section{RESUMO}

Este estudo apresenta fundamentação teórica e seus desdobramentos no currículo de formação inicial em Educação Física para atuar na Educação Básica, implementado no Centro de Educação Física e Desportos da Universidade Federal do Espírito Santo, em 2006.

PALAVRAS-CHAVE: formação inicial - educação física - currículo

\section{INTRODUÇÃO}

Neste ano de 2006, o Centro de Educação Física e Desportos da Universidade Federal do Espírito Santo (CEFD/UFES) completa 75 anos, formando professores de Educação Física. Na avaliação de Silva (1991), por várias vezes, ao longo de sua história, essa instituição parece ter estado à frente das discussões de seu tempo, participando, ativamente, do debate nacional nas questões que lhe eram afetas. Nas décadas de 1930 e 1940, por exemplo, a questão da pedagogia e do método a ser adotado, nacional e oficialmente, esteve na pauta. Na década de 1980, com uma legislação já obsoleta, fazia-se presente, no currículo vivido, o esforço, de parte de seu corpo docente, em sintonizar a formação de professores com o debate de ponta que assolava a Educação Física brasileira, na sua propalada crise de identidade. Ao final dessa década, e, principalmente na seguinte, delineou-se, no CEFD, um esforço orquestrado em prol da qualificação de seu corpo docente, visando criar condições que permitissem investir num processo de formação

* Centro de Educação Física e Desportos da Universidade Federal do Espírito Santo.

** Os autores são professores do CEFD/UFES e integraram a Comissão de Reestruturação Curricular. 
crítico e reflexivo, com professores comprometidos com uma Educação Física crítica e com a educação pública e democrática, elementos capazes, mas não únicos, de fomentar a formação humana tendo como base a educação para a cidadania.

O esforço coletivo empreendido nesses últimos anos parece, em 2006, apresentar à comunidade interna e externa da UFES suas colaborações mais efetivas no que tange à formação inicial e continuada. Com relação à primeira, estamos em fase de implementação do novo currículo para formação de professores de Educação Física para atuar na educação básica, nas modalidades presencial e a distância; quanto à segunda, o CEFD tem desenvolvido diferentes iniciativas, dentre elas, cursos de pós-graduação lato sensu, grupos de estudo e extensão universitária, parceria com prefeituras, e, mais recentemente, a aprovação e implementação da pós-graduação stricto sensu.

O presente artigo torna visível uma dessas iniciativas, a saber, o currículo novo para a formação inicial, elaborado a partir do diálogo com a literatura, dos estudos que vimos desenvolvendo sobre a formação inicial no CEFD e das indicações legais vigentes. O Projeto Curricular deriva do trabalho coletivo da Comissão de Reestruturação Curricular, ${ }^{1}$ que teve como tarefas: a) estudar e sistematizar a legislação que fornece as diretrizes curriculares para os cursos de educação física e para a formação de professores para atuar na educação básica; b) sistematizar o debate sobre formação profissional docente e currículo; c) examinar as iniciativas de reformulação curricular ocorridas no CEFD apoiadas na Resolução 03/87; d) elaborar proposta curricular com respaldo das ações anteriores.

A proposta apresentada à comunidade acadêmica interna do CEFD foi debatida em diferentes fóruns, recebendo e equacionando às críticas e sugestões que lhe foram dirigidas por escrito, conforme a dinâmica de discussão proposta. O texto final foi apreciado nas instâncias oficiais devidas, tornando-se, então, o Projeto Curricular oficial do curso.

Nesse nosso esforço de síntese, duas noções abraçadas no currículo precisam ser registradas. A noção de currículo, que nos fundamenta, contempla a diversidade cultural, a construção da identidade e da subjetividade no espaço de aula, a interação professor-alunos, nas relações pessoais e sociais, históricas e políticas. Visualizamos o currículo como "prática que se expressa em comportamentos práticos diversos" (SACRISTÁn, 2000, p. 16). Assim, o significado de currículo 
como prática pedagógica está impregnado pelas diversas práticas escolares; ele é percebido no cruzamento dessas práticas nas aulas, nas escolas e nas instituições que formam professores. Já a noção de formação profissional busca trazer para o âmbito da formação inicial a compreensão das complexas relações presentes no cotidiano e na cultura escolar. Acreditamos numa formação que considere o professor ator ativo de suas práticas pedagógicas, e que "em sua trajetória, constrói e reconstrói seus conhecimentos conforme a necessidade de utilização dos mesmos, suas experiências, seus percursos formativos e profissionais" (NuNES, 2001, p. 27).

Dito isso, apresentamos o Projeto Curricular do CEFD/UFES, discutindo problemas comuns à formação em Educação Física, a legislação referente à formação profissional, os pressupostos norteadores da reformulação curricular que se constituíram como eixo teórico da formação oferecida e a matriz e a organização curricular do curso.

\section{PROBLEMAS COMUNS À FORMAÇÃO EM EDUCAÇÃO FÍSICA}

Os dilemas comumente abordados na formação inicial nas licenciaturas transitam entre os seguintes problemas: falta de articulação teoria e prática e unidade no processo de formação; dicotomia entre formação específica e formação pedagógica; necessidade de construção de uma sólida formação aliada ao compromisso social do professor como intelectual crítico e agente de transformação social; necessidade de políticas públicas que integrem Estado, instituições formadoras e instituições que contratam profissionais da educação; desarticulação entre a formação inicial e formação continuada; desvalorização da habilitação em licenciatura frente à habilitação em bacharelado.

$\mathrm{Na}$ formação inicial em Educação Física, nos cursos de licenciatura, a esses problemas somam-se outros, como a ausência de uma identidade profissional específica e a falta de clareza do seu objeto de estudo. A formação tem sido marcada por uma tendência generalista para abranger diversidade da ação profissional; por uma estrutura curricular que beneficia a fragmentação do conhecimento e a valorização de disciplinas de cunho biológico em detrimento do conteúdo disciplinar das Ciências Humanas; e pela ênfase na formação técnico-esportiva. 
Além disso, a estreita vinculação entre Educação Física/saúde, relacionada apenas com o aspecto biológico, e Educação Física/esporte, relacionada apenas à questão da performance, tem sido, ao longo dos anos, a principal referência dos alunos que ingressam no curso. Essa referência é um dos principais entraves para que se possa compreender a dimensão educacional da Educação Física e suas interfaces com diferentes campos de saberes. Esses e outros problemas são discutidos por estudiosos da área há, pelo menos, três décadas.

Estudos realizados nos anos 70-80 abordaram problemas pertinentes à formação profissional em Educação Física com certa criticidade e a favor de repensar a formação do ponto de vista do compromisso social do profissional e não apenas de sua capacitação técnica. Denunciaram o processo de formação profissional acrítico, ahistórico e acientífico; a fragmentação do conhecimento; a dicotomia entre teoria e prática; a importação de modelos teóricos de forma descontextualizada e acrítica; a organização curricular com base na formação esportiva calcada no paradigma da aptidão física, dentre outros. Vários deles preocuparam-se com análises de currículos específicos de cursos e com a enfática discussão licenciatura/generalista versus bacharelado/especialista.

Os problemas denunciados na produção da década de 1980 motivaram a configuração de um clima de reformas e revisões, colocando a temática curricular no centro das atenções. Essa discussão ainda se faz presente na área, entretanto, as análises de currículo prescrito cedem lugar a preocupações com a prática pedagógica na formação e em outros níveis de ensino; aos estudos sobre o distanciamento entre formação inicial e realidade educacional; à identidade profissional; ao processo de formação do professor de Educação Física; à constituição dos saberes docente; além de apresentar um crescimento significativo na utilização de referenciais da Educação em pesquisas da área.

A produção veiculada a partir dos anos 90 adentra problemáticas pedagógicas dos cursos de formação. Discutem-se modelos curriculares e proposta de um modelo de ensino reflexivo; reflete-se sobre as disciplinas científicas na grade curricular e atitudes dos professores dessas disciplinas. Aos poucos, fazem-se perceptíveis investigações centradas nos problemas pertinentes à formação inicial do professor de Educação Física e a prática pedagógica de professores formadores e/ou professores de Educação Física atuantes em Educação Infantil, Ensi- 
no Fundamental e Médio. Nesse movimento, a identidade profissional encontra-se definida na docência e pautada em uma Educação Física que pode ser compreendida como área que tematiza as práticas corporais em suas dimensões culturais, sociais e biológicas, extrapolando a questão da saúde, relacionando-se com as produções culturais que envolvem aspectos lúdicos e estéticos, deixando de ter como foco apenas o esporte ou os exercícios físicos voltados para uma perspectiva restrita de performance.

Contudo, tanto do ponto de vista da profissão, quanto do ponto de vista do professor e de sua formação, esse processo de construção de novos referenciais para a Educação Física tem sofrido entraves. Do ponto de vista da profissão, o entrave maior refere-se à desvalorização da profissão docente (NóvoA, 1997); do ponto de vista do professor e de sua formação, dentre todos os problemas apontados anteriormente no processo de formação, destacamos, nessa reflexão, a indefinição do perfil do profissional de Educação Física que se quer formar, representada pelo velho dilema entre bacharelado e licenciatura. Para tratar a problemática que envolve as diretrizes curriculares e a formação profissional em cursos de educação física, balizamos nossa reflexão na historicização do dilema do perfil da formação profissional (licenciatura $\mathrm{x}$ bacharelado) e no exame da configuração que originaram a legislação atual.

\section{DIRETRIZES CURRICULARES E CURSOS DE EDUCAÇÃO FÍSICA}

Foi preciso examinar a conjuntura que marcou a publicação das orientações legais vigentes para fazermos opções político-pedagógicas para a proposição de um novo currículo, em licenciatura, para o CEFD/ UFES. Nesse espaço, podemos apenas chamar atenção para o fato de que o debate da pertinência da formação em dois níveis - licenciatura e bacharelado/graduado -, envolvendo tanto questões epistemológicas como aquelas afetas à formação profissional, foi interrompido com a publicação dos Pareceres e Resoluções referentes à formação de professores para atuar na Educação Básica. Esse debate teve origem na Resolução n. 03/87. ${ }^{2}$ As Resoluções 01/2002 e 02/2002 desautorizaram a tese de formação em licenciatura plena generalista, já que, a partir de suas orientações, não era possível mais, a nenhum curso, sobrepor/ conjugar a formação de bacharéis e licenciados. Em síntese, no caso 
da Educação Física, significou que resoluções externas acabaram por definir o seu impasse frente ao seu velho dilema de perfil profissional.

Com a publicação dos Pareceres n. 583/2001 e n. 009/2001, a discussão das diretrizes curriculares dos cursos de licenciatura tomou novos rumos. $\mathrm{O}$ primeiro indicou que as diretrizes curriculares contemplassem: a) perfil do formado/egresso/profissional desejado; b) competências/habilidades/atitudes; c) habilitações e ênfases; d) conteúdos curriculares; e) organização do curso; f) estágios e atividades complementares; g) acompanhamento e avaliação. O segundo estabeleceu as Diretrizes Curriculares Nacionais para a Formação de Professores da Educação Básica, em nível superior.

Com o Parecer n. 009/2001, a licenciatura ganha "terminalidade e integralidade própria em relação ao Bacharelado, constituindo-se em um projeto específico. Isso exige a definição de currículos próprios da Licenciatura que não se confundam com o Bacharelado ou com a antiga formação de professores que ficou caracterizada como modelo ' $3+1$ '”, (Parecer n. 009 do CNE/CP, 2001, p. 6). Vale destacar que ele partiu do entendimento de que a Educação é responsável pelo desenvolvimento das pessoas e da sociedade e pelo favorecimento de transformações sociais necessárias. Dentre outras diretrizes, apontou a concepção de escola, de alunos, de profissão magistério e de formação de professores que deveria ser assumida nos cursos de licenciatura.

O eixo norteador dessas diretrizes perpassa os pressupostos de uma educação inovadora que ofereça bases culturais a alunos e professores para a construção de uma cidadania consciente e ativa. O professor é compreendido como profissional do ensino, agente ativo de suas próprias práticas pedagógicas e conhecedor da necessidade de uma formação permanente ao longo de sua carreira docente, incluindo a pesquisa como elemento essencial.

No que se refere à organização da matriz curricular, esse Parecer indica as seguintes diretrizes para as IES: pensar formas inovadoras de organização dos conhecimentos para além da organização em disciplinas; promover atividades coletivas e interativas de comunicação entre os professores em formação e os professores formadores; incentivar estudos disciplinares que possibilitem a inter-relação entre os conhecimentos mobilizados na formação; articular a formação comum com a formação específica; articular os conhecimentos educacionais e pe- 
dagógicos com os conhecimentos de formação específica; e articular teoria e prática desde o início da formação.

Além da formação específica correspondente ao objeto de ensino de cada licenciatura, os cursos de formação devem contemplar: cultura geral e profissional; conhecimentos sobre a criança, adolescentes, jovens e adultos, incluídas as especificidades dos alunos com necessidades especiais e as das comunidades indígenas; conhecimento sobre a dimensão cultural, social, política e econômica da educação; conhecimento pedagógico; conhecimento advindo da experiência. Essas orientações consubstanciaram a publicação da Resolução 01/2002 que instituiu as diretrizes curriculares nacionais para a formação de professores da educação básica, em nível superior, curso de licenciatura, de graduação plena.

Cabe por fim, uma palavra sobre a legislação oriunda da área específica. Em 2001, a SESu retomou os trabalhos de elaboração de propostas curriculares para algumas áreas, dentre elas a de Educação Física. Entretanto, no caso da nossa área, tudo indica que ignorou a proposta da CO$\mathrm{ESP} / \mathrm{EF}$ e agrupou os trabalhos de elaboração das propostas por blocos de carreira, considerando o critério utilizado pela Coordenação de Aperfeiçoamento de Pessoal de Ensino Superior (CAPES), o que fez a Educação Física ficar reunida aos cursos das Ciências Biológicas e Saúde.

A ação de situar a Educação Física na área da saúde, com a efetiva transferência de responsabilidades na elaboração de propostas da COESP/ EF para uma Comissão da Área de Saúde, gerou distorções: comprometeu a possibilidade de compreender a interface da Educação Física com diferentes campos de saberes e a formação de seus profissionais em uma dimensão educacional; abriu a possibilidade para que professores alheios ao debate epistemológico interferissem e decidissem sobre questões caras à formação desse profissional, muitas delas já superadas internamente; resultou em uma proposta cujo perfil profissional encontra-se indefinido, mas muito próximo ao perfil de profissionais da área da saúde. Esse perfil é expresso no Parecer n. 138/2002, que esboçou uma proposta de formação em Educação Física pautada nas diretrizes Curriculares dos Cursos de Graduação da Saúde.

Ainda que aprovado no Conselho Nacional de Educação, esse Parecer recebeu muitas manifestações contrárias às diretrizes propostas. Várias delas foram colocadas para discussão e disputaram espaço 
no jogo de correlação de grupos constituídos no campo da Educação Física brasileira. A indicação de outra COESP/EF foi resultado desse movimento contrário ao Parecer. Essa Comissão teve como finalidade analisar e propor reformulações nas premissas conceituais necessárias à discussão curricular em Educação Física e de seus trabalhos resultou o Parecer n. 058/2004.

O novo Parecer não restringe a caracterização da área à sua dimensão biológica no campo da saúde, possibilitando as IES escolha da matriz epistemológica orientadora de seu(s) currículo(s) de formação em Educação Física. Ele consubstanciou a publicação da Resolução n. 7/2004, que, somada àquelas pertinentes às diretrizes para formação de professores, impulsionaram os cursos de Educação Física a (re)estudar seus currículos.

\section{CONSTRUINDO O EIXO TEÓRICO PARA A LICENCIATURA}

Nossa preocupação nesse tópico é destacar duas importantes contribuições nas quais se apoiaram nossa reflexão para a elaboração da matriz curricular. A primeira delas diz respeito às discussões inerentes à formação do professor - de educação física - para atuar na educação básica. A segunda, a perspectiva da construção do saber docente apoiado em práticas dialógicas que favoreçam a compreensão do saberfazer escolar. Para tanto, levamos em consideração uma significativa produção em Educação Física escolar que indica suas interfaces com os diferentes campos de saberes das Ciências Humanas, estudos recentes sobre a formação do professor de Educação Física, e revisitamos, na educação, o debate da construção do conhecimento na perspectiva pluri/interdisciplinar.

A formação docente é tratada por diferentes perspectivas teóricas. Destacamos duas que contêm pressupostos fundamentais para o processo de formação proposto. A primeira é aquela que dá ênfase à profissão docente, isto é, privilegia o estudo do coletivo profissional e do campo acadêmico profissional. A segunda tem como objeto o ser professor, sua individualidade, sua subjetividade, sua história de vida, sua trajetória na escola, sua atuação profissional. Estas perspectivas estão interligadas. 
$\mathrm{Na}$ perspectiva de análise da profissão docente, consideramos que vivemos um processo acelerado de proletarização que "provoca uma degradação do estatuto, dos rendimentos e do poder/autonomia" (NóvoA, 1997, p. 24) do professorado, mas, ao mesmo tempo, a intensificação de um processo de construção de uma identidade docente centrada, também, na natureza do trabalho docente que é ensinar como contribuição ao processo de humanização de alunos historicamente situados, ensinar como processo que desenvolva e permita aos alunos construírem conhecimentos, atitudes, habilidades, valores (PIMENTA, 2000); ensinar como processo de construção de compromissos que possibilitem a reflexão e ação no sentido de provocar mudanças sociais necessárias à construção de uma sociedade melhor.

Se abordamos a formação docente na perspectiva de análise de ser professor, é possível enfocar sua história de vida, o ensino, o currículo, os saberes que constituem a docência, dentre outros. Decidimos aqui privilegiar os saberes que constituem a docência por entendermos que o (não) entendimento dessa questão representa, hoje, um dos grandes problemas no âmbito da Educação Física.

Seguindo os estudos de Pimenta (2000), sabemos que os saberes da docência são constituídos pela experiência, pelo conhecimento e pelos saberes pedagógicos. A experiência que o licenciando transporta para o curso de formação advém da sua vida escolar. Em sua trajetória escolar, o aluno constitui relações e formas de ver o mundo que lhe permitem saber o que representa ser professor para a nossa sociedade (desvalorização social, financeira) ou, ainda, avaliar quais são os bons professores, quais sabem o conteúdo, mas não sabem ensinar. O conhecimento diz respeito ao saber específico de cada área que o professor deve dominar para ensinar bem. Os saberes pedagógicos não se reduzem à didática ou às metodologias; significam construção de saberes na relação cotidiana escolar, a partir das necessidades pedagógicas colocadas pela prática social da educação.

Podemos dizer, então, que a prática docente é pedagógica e que constrói relações sociais nas quais o professor possui um compromisso social com a ação de ensinar como contribuição ao processo de humanização dos alunos. Toda prática pedagógica tem uma intencionalidade consciente ou inconsciente responsável pela formação humana e que pode contribuir para modificar as relações sociais 
existentes. A construção/produção dessa prática pedagógica se nutre de aspectos analisados tanto pela perspectiva teórica da profissão docente, como pela perspectiva de ser professor.

O estudo de Figueiredo (2003) identificou que as experiências construídas pelos licenciandos do CEFD/UFES, antes do ingresso no curso, contribuem para a construção de uma representação do que seja compromisso social do professor de Educação Física. Essa representação se pauta no modo como os professores de Educação Física, no ensino fundamental e no ensino médio, selecionam, planejam, organizam, transmitem e avaliam os conhecimentos específicos da área. Esses procedimentos favorecem a construção de um tipo de relação com a disciplina em que prevalecem concepções unilaterais de que Educação Física é esporte, de que Educação Física é saúde, favorecendo, ainda, a manutenção de crenças e mitos que influenciam diferentes visões, hierarquizações e trajetórias relacionadas às experiências sociocorporais.

É sabido que essa representação influencia nas escolhas acadêmicas e profissionais ao longo do processo de formação. Mas não só. Destacamos que esse modo de seleção, planejamento, organização, transmissão e avaliação dos conhecimentos tem motivado os alunos a buscar, fora da escola, atividades que preencham o vazio deixado pela disciplina de Educação Física na educação básica.

$\mathrm{Na}$ formação profissional, essas experiências construídas na educação básica nas aulas de Educação Física, funcionam como filtros que perpassam a dinâmica curricular durante todo o curso. Há um prolongamento dessas experiências e a formação oferecida parece revelar-se frágil e reprodutora dessas experiências trazidas para dentro do curso. Nesse caso, então, o processo de formação inicial deve tentar romper com as concepções incorporadas e transferidas para os cursos, bem como deve ser decisiva na construção do compromisso social e político dos futuros professores que irão atuar na escola. Essa, talvez, seja uma das condições de possibilidade mais promissoras - evidentemente, não a única - para que se modifique, num trabalho de médio e longo prazo, a própria representação da disciplina e de ser professor de educação física.

No que tange à perspectiva da construção do saber docente apoiado em práticas dialógicas que favoreçam a compreensão do saberfazer escolar, considerou-se a possibilidade de flexibilização curricular 
e a necessidade de "articulação" entre teoria e prática nos cursos de formação docente, buscando operar com uma perspectiva teórica que privilegia uma concepção acrítica de disciplinas acadêmicas e escolares. Estas entendidas, comumente, como conjunto de conhecimentos articulados como uma matéria de ensino - na escola - ou como um ramo do conhecimento - na perspectiva acadêmica. Neste caso, a disciplinaridade é vista como artefato da racionalidade científica, produtora de saberes (altamente) especializados que promoveriam fragmentação de objetos a conhecer e, em última instância, dada essa dispersão, a impossibilidade de entendimento do humano.

A idéia de interdisciplinaridade não é nova e promove debate acirrado, tanto no plano epistemológico, como no pedagógico e, mais especificamente, noplano curricular. Desse debate, interessa-nos destacar que uma vertente crítica da Filosofia do Conhecimento tomou como alvo de seus questionamentos a questão da fragmentação do objeto. Assim, na síntese de Veiga Neto (1996, p. 130), “o que parecia haver de errado com os currículos clássicos - [isto é, disciplinares por excelência] - era o fato de que separavam os diferentes saberes entre si". Para superar a questão, a saída proposta era desfragmentar o conhecimento, fundindoos naquilo que se popularizou como interdisciplinaridade, que seria a antítese do saber especializado.

Outra vertente crítica da Filosofia do Conhecimento tem colocado a questão em outros termos, qual seja: o problema talvez não esteja na fragmentação do conhecimento, mas nos usos dessa fragmentação. Um deles foi, por exemplo, ter promovido, em nome de uma neutralidade científica fictícia, o descompromisso da produção do conhecimento com a formação humana. Essa vertente questiona a viabilidade da proposta interdisciplinar de produção do conhecimento, mas reconhece que a colocação da interdisciplinaridade no horizonte do plano acadêmico - e escolar - criou condições de possibilidade para que, de fato, se construísse uma atitude dialógica entre as disciplinas/matérias de ensino e não uma superciência (FAZENDA, 1993).

Foi essa atitude dialógica entre disciplinas acadêmicas, para abordar questões afetas à escola, à educação e à pedagogia e à educação física, que o novo currículo assumiu. Assim, prescindiuse de disciplinas acadêmicas sobrepostas às disciplinas curriculares, que, por vezes, centram discussão em seus objetos e teorias clássicas. Não prescindiu-se, entretanto, da colaboração que os conhecimentos 
produzidos pelas disciplinas acadêmicas podem trazer ao conhecimento do processo de humanização. Buscou-se articular esses conhecimentos em atitude dialógica nas disciplinas curriculares, o que impõe/sugere a necessidade de que os professores-formadores assumam, também, a responsabilidade de promover tal diálogo, tendo como eixo articulador a problemática da formação humana, da escola e do ensino.

No novo currículo, as disciplinas curriculares são obrigatórias, perspectivadas na e com atitude dialógica, e contemplam os conhecimentos da Formação Comum e do Conhecimento da Área. ${ }^{3}$ Além delas, assumiu-se outras formas para construção e experimentação do conhecimento necessário à formação de professores de educação física. São elas: seminários de estudo para introdução e/ou aprofundamento de determinado tema, ${ }^{4}$ seminários articuladores das disciplinas curriculares de cada semestre do curso, ${ }^{5}$ oficinas ${ }^{6}$ e outros projetos e atividades que integram os conhecimentos advindos da experiência e de cultura geral e profissional. ${ }^{7}$ Essas dinâmicas do processo formativo foram inspiradas pela noção de currículo intensivo, proposta por Demo (1997), e materializam a matriz curricular do curso.

\section{ORGANIZAÇÃO E GRADE DO NOVO CURRÍCULO DE LICENCIATURA}

Considerando o eixo teórico e matriz, o currículo foi organizado por eixos, com cargas horárias e ementas para as disciplinas ${ }^{8}$ e atividades, posteriormente, configurando-se a grade curricular. Assim temos:

- Cultura Geral e Profissional: atividades acadêmico-culturais desenvolvidas em seminários, congressos e projetos de pesquisa. Esses conhecimentos são contemplados com a participação nas seguintes modalidades eventuais: 1. Participação em eventos inerentes ao curso de licenciatura em Educação Física do CEFD/UFES, na forma de seminários de estudos, oferecidos por professores vinculados à licenciatura, derivados de suas pesquisas e que se proponham a estudar questões afetas à Educação Física Escolar. Os seminários não têm caráter disciplinar e devem fomentar a formação de professores-pesquisadores da sua própria prática. Podem abrigar os trabalhos desenvolvidos no interior de grupos de estudo. 2. Participação em eventos externos ao curso de licenciatura em Educação Física do CEFD/UFES. 
- Formação Comum: contempla o conhecimento de três grandes temáticas. O Eixo I aborda o conhecimento cultural, social, político e econômico da Educação e Educação Física e é composto pelas seguintes disciplinas curriculares: Educação Escolar, Educação Física e Reflexão Filosófica; Educação Física, Educação e Escolarização; Família, Educação Escolar, Educação Física e Sociedade, Políticas Públicas da Educação Básica. O Eixo II discute conhecimentos sobre crianças, jovens e adultos. São suas disciplinas: Educação e Inclusão; Corpo, Movimento e Escolarização $;{ }^{9}$ Teorias de Aprendizagem e Desenvolvimento Humano em Educação Física. O Eixo III refere-se ao conhecimento pedagógico e tem como disciplinas curriculares Educação Física, Formação Docente e Currículo; Pensamento Pedagógico Brasileiro e Fundamentos da Didática; Educação Física, Conhecimento e Cultura Escolar.

- Conhecimento de Área: oportuniza o estudo da Educação Física como área do conhecimento e dos objetos de ensino em cada uma das diferentes etapas da Educação Básica. O Eixo I, nominado Teoria da Educação Física, apresenta a discussão epistemológica sob a qual se articula a área de conhecimento Educação Física. As disciplinas curriculares que a compõem são: Introdução à Educação Física, Educação Física e Escola e Epistemologia da Educação Física. O Eixo II, Corpo $\boldsymbol{e}$ Movimento, apresenta as possibilidades de fundamentação e estudo do corpo em movimento, a partir de dois sub-eixos. Um preponderantemente calcado nas ciências biológicas, contempla as disciplinas Corpo, Movimento e Conhecimentos Biológicos, Corpo, Movimento e Conhecimentos Morfológicos, Corpo, Movimento e Conhecimentos Fisiológicos e Comportamento Motor. O outro, apoiado nas ciências humanas e sociais, congrega as disciplinas Educação Física, Corpo e Movimento; Corpo, Expressão e Linguagem e Educação Física, Adaptação e Inclusão. O Eixo III e o Eixo $\mathbf{V}$ apresentam e articulam (juntamente com o Estágio Supervisionado) as práticas necessárias à formação do professor-pesquisador e recebem, respectivamente, os nomes de Pedagogia da Educação Física e Pesquisa em Educação Física. Compõem o primeiro, as disciplinas de Metodologia do Ensino da Educação Física; Ensino da Educação Física na Educação Infantil; Ensino da Educação Física no Ensino Fundamental I; Ensino da Educação Física no Ensino Fundamental II; Ensino da Educação Física no Ensino Médio. Já o segundo, Pesquisa e Docência em Educação Física, Seminário de 
Monografia I, Seminário de Monografia II e os sete Seminários Articuladores de Conhecimento. O Eixo IV, que discute diferentes práticas corporais submetidas ao processo de escolarização, foi nominado Práticas Corporais e Forma Escolar e congrega as seguintes disciplinas: Teoria e Prática do Jogo; Teoria e Prática da Dança; Teoria e Prática da Ginástica Geral; Teoria e Prática dos Esportes Coletivos e Teoria e Prática dos Esportes Individuais.

- Estágio Supervisionado (ES): inserção efetiva no trabalho escolar, potencializando a reflexão teórico-prática da docência e das práticas escolares. O estágio permite a problematização, investigação e intervenção sobre o/no cotidiano escolar em diferentes níveis no ensino da Educação Física na Educação Básica.

- Conhecimento Advindo da Experiência (CAE): está relacionado às práticas próprias da atividade docente articuladas ao conhecimento teórico e corresponde a 400 horas vivenciadas pelos licenciandos, com envolvimento efetivo, nas seguintes situações didáticas: Projetos desenvolvidos no interior das disciplinas do curso; projetos desenvolvidos em disciplinas de outros cursos de licenciatura; participação em estudos/pesquisas que tenham como foco a realidade escolar e favoreçam a vivência, observação e reflexão das práticas de pesquisa e docência em Educação Física; projetos de Extensão e nas Oficinas oferecidas pelo curso.

Por fim, apresentamos a grade curricular, informando que a distribuição de horários ocupa o turno diurno, pela manhã (7:00 às 12:00 horas) concentradas as disciplinas curriculares e Oficinas, e, pela tarde (13:00 às 15:00 horas, preferencialmente), os Seminários de Estudo, o Seminário Articulador de Conhecimentos e as atividades de CAE.

\begin{tabular}{|c|c|c|c|}
\hline $1^{\circ}$ período & $2^{\circ}$ período & $3^{\circ}$ período & $4^{\circ}$ período \\
\hline Introdução à EF & $\begin{array}{c}\text { Educação Física e } \\
\text { Escola }\end{array}$ & $\begin{array}{c}\text { Pesquisa e } \\
\text { Docência em EF }\end{array}$ & $\begin{array}{c}\text { Seminário de } \\
\text { Monografia I }\end{array}$ \\
\hline $\begin{array}{c}\text { EF, Corpo e } \\
\text { Movimento }\end{array}$ & $\begin{array}{c}\text { Comportamento } \\
\text { Motor }\end{array}$ & $\begin{array}{c}\text { Metodologia do } \\
\text { Ensino da EF }\end{array}$ & $\begin{array}{c}\text { Teoria e Prática da } \\
\text { Gin. Geral }\end{array}$ \\
\hline Corpo, Mov. e & Corpo, Mov. e & Corpo, Mov. e & Teoria e Prática da \\
Conh. Biol. & Conh. Morfol. & Conh. Fisiol. & Dança \\
\hline $\begin{array}{c}\text { EF, Form. Docente } \\
\text { e Currículo }\end{array}$ & Psicologia da & Educação e & Ensino da EF na \\
Educação & Inclusão & Edfantil \\
\hline $\begin{array}{c}\text { Teorias da Ap e do } \\
\text { Des. Humano }\end{array}$ & $\begin{array}{c}\text { EF, Educação e } \\
\text { Reflexão Filos. }\end{array}$ & $\begin{array}{c}\text { Corpo, Mov. e } \\
\text { Escolarização }\end{array}$ & $\begin{array}{c}\text { ES da EF na Ed. } \\
\text { Infantil }\end{array}$ \\
\hline
\end{tabular}




\begin{tabular}{|c|c|c|c|}
\hline $\begin{array}{c}\text { Seminário } \\
\text { Articulador I }\end{array}$ & $\begin{array}{c}\text { Seminário } \\
\text { Articulador II }\end{array}$ & $\begin{array}{c}\text { Seminário } \\
\text { Articulador III }\end{array}$ & $\begin{array}{l}\text { Pens. Ped. e Fund. } \\
\text { da Did. }\end{array}$ \\
\hline Oficinas Grupo 1 & Oficinas Grupo 1 & Oficinas Grupo 1 & $\begin{array}{c}\text { Seminário } \\
\text { Articulador IV }\end{array}$ \\
\hline Oficinas Grupo 2 & Oficinas Grupo 2 & Oficinas Grupo 2 & Oficinas Grupo 1 \\
\hline $\begin{array}{c}\text { Seminário } \\
\text { Introdutório }\end{array}$ & $\begin{array}{c}\text { Seminário de } \\
\text { Aprofundamento }\end{array}$ & $\begin{array}{c}\text { Seminário de } \\
\text { Aprofundamento }\end{array}$ & Oficinas Grupo 2 \\
\hline Atividades de CAE & Atividades de CAE & Atividades de CAE & $\begin{array}{c}\text { Seminário de } \\
\text { Aprofundamento }\end{array}$ \\
\hline $5^{\circ}$ período & $6^{\circ}$ período & $7^{\circ}$ período & Atividades de CAE \\
\hline $\begin{array}{c}\text { EF, Adaptação e } \\
\text { Inclusão }\end{array}$ & $\begin{array}{c}\text { Corpo, Expressão e } \\
\text { Linguagem }\end{array}$ & $\begin{array}{c}\text { Teoria e Prática dos } \\
\text { Esportes Ind. }\end{array}$ & $8^{\circ}$ período \\
\hline $\begin{array}{c}\text { Teoria e Prática do } \\
\text { Jogo }\end{array}$ & $\begin{array}{c}\text { Teoria e Prática dos } \\
\text { Esportes Col } \\
\end{array}$ & $\begin{array}{c}\text { Ensino da EF no } \\
\text { Ens. Médio }\end{array}$ & $\begin{array}{l}\text { Seminário de } \\
\text { Monografia II }\end{array}$ \\
\hline $\begin{array}{c}\text { Ensino da EF no } \\
\text { Ens. Fund. I }\end{array}$ & $\begin{array}{c}\text { Ensino da EF no } \\
\text { Ens. Fund. II }\end{array}$ & $\begin{array}{c}\text { ES na EF no Ens. } \\
\text { Médio }\end{array}$ & $\begin{array}{c}\text { Epistemologia da } \\
\text { EF }\end{array}$ \\
\hline $\begin{array}{c}\text { ES na EF no Ens. } \\
\text { Fund. I }\end{array}$ & $\begin{array}{c}\text { ES na EF no Ens. } \\
\text { Fund. II }\end{array}$ & $\begin{array}{c}\text { Políticas Públicas } \\
\text { da Ed. Básica }\end{array}$ & $\begin{array}{l}\text { EF, Educação e } \\
\text { Escolarização }\end{array}$ \\
\hline $\begin{array}{l}\text { Conhecimento e } \\
\text { Cultura Escolar }\end{array}$ & $\begin{array}{c}\text { Família, Educação } \\
\text { e Sociedade }\end{array}$ & $\begin{array}{c}\text { Seminário } \\
\text { Articulador VII }\end{array}$ & $\begin{array}{c}\text { Seminário } \\
\text { Articulador VIII }\end{array}$ \\
\hline $\begin{array}{c}\text { Seminário } \\
\text { Articulador V }\end{array}$ & $\begin{array}{c}\text { Seminário } \\
\text { Articulador VI }\end{array}$ & Oficinas Grupo 1 & Oficinas Grupo 1 \\
\hline Oficinas Grupo 1 & Oficinas Grupo 1 & Oficinas Grupo 2 & Oficinas Grupo 2 \\
\hline Oficinas Grupo 2 & Oficinas Grupo 2 & $\begin{array}{c}\text { Seminário de } \\
\text { Aprofundamento }\end{array}$ & $\begin{array}{c}\text { Seminário de } \\
\text { Aprofundamento }\end{array}$ \\
\hline $\begin{array}{c}\text { Seminário de } \\
\text { Aprofundamento }\end{array}$ & $\begin{array}{c}\text { Seminário de } \\
\text { Aprofundamento }\end{array}$ & Atividades de CAE & Atividades de CAE \\
\hline Atividades de CAE & Atividades de CAE & & \\
\hline
\end{tabular}

\section{Initial Education and Syllabus at CEFD/UFES}

\section{ABSTRACT}

This study presents the theoretical recital and its unfoldings in the syllabus of the initial education program in Physical Education for Primary Education as it was implemented at CEFD/UFES (the Center for Physical Education and Sports at Universidade Federal do Espirito Santo in the year 2006.

KEYWORDS: initial education - physical education - course syllabus 


\section{Formación Inicial y Currículo en el CEFD/UFES}

\section{RESUMEN}

Este estudio presenta la fundamentación teórica y sus desdoblamientos en el currículo de formación inicial en Educación Física para actuar en la Educación Básica (Brasil) implementado en el Centro de Educación Física y Deportes de la Universidad Federal de Espíritu Santo en 2006.

PALABRAS-CLAVE: formación inicial - educación física - currículo

\section{NOTAS}

1 Além dos autores, compuseram a Comissão os acadêmicos Rosemary Pereira de Oliveira e Walk Loureiro.

2 Em 1997 foi nomeada uma Comissão de Especialistas de Ensino em Educação Física (COESP/EF) com a finalidade de elaborar as novas diretrizes curriculares da área. Essa Comissão tomou a Resolução n. 03/87 como ponto de partida dos trabalhos e tentou avançar em relação aos problemas apontados na interlocução com os cursos de Educação Física. Por meio do Edital n. 05, de 4 de março de 1998, foi solicitado aos cursos superiores de educação física que apontassem os limites da Resolução n. 03/87, bem como sugestões e/ou contribuições para a sua reformulação.

3 A Formação Comum contempla conhecimentos sobre crianças, jovens e adultos, conhecimentos sobre a dimensão cultural, social, política e econômica da educação, conhecimentos pedagógicos. $\mathrm{O}$ Conhecimento de Área contempla a discussão epistemológica da Educação Física e os objetos de ensino em cada uma das diferentes etapas da Educação Básica.

4 Seminário Introdutório e/ou de Aprofundamento é a unidade curricular que formaliza o tempo oficialmente dedicado ao estudo de uma determinada temática, extraída e/ou derivada das discussões levantadas em disciplinas curriculares obrigatórias e/ou em estudos desenvolvidos nos grupos de pesquisa ligados aos CEFD/UFES. Os seminários de estudos promovidos nessa unidade curricular têm como principal objetivo levar os acadêmicos a refletir de modo sistematizado sobre determinada problemática, a partir da leitura compartilhada de uma bibliografia específica. Eles são optativos - o licenciando pode ter que escolher um entre os diferentes seminários oferecidos - e as cargas 
horárias cumpridas poderão ser computadas nas 200 horas de atividades acadêmico-culturais do eixo Cultura Geral e Profissional.

5 Unidade curricular que oficializa um tempo de reflexão coletiva com os acadêmicos de cada turma, por período. Eles são obrigatórios e tem a finalidade de articular os saberes mobilizados nas respectivas disciplinas curriculares obrigatórias ofertadas a cada semestre. A idéia central dessa unidade curricular é que professores que estudem o processo de formação inicial possam acompanhar e promover o debate sobre o processo de construção/produção do conhecimento vivido e necessário à formação do professor de educação física que irá atuar na educação básica. É um momento de diálogo, que privilegia a exposição - e a escuta - da percepção que os licenciandos estão tendo do seu processo de formação para que, a partir dessa escuta, possam ser produzidas síntese coletivas e significativas do conhecimento vivido para que ele se torne praticado.

6 Unidade curricular que garante o tempo institucional de vivência de práticas corporais que constituem objetos de ensino específicos da área. As oficinas são optativas - os licenciando optam entre aquelas oferecidas no semestre - e devem considerar o eixo curricular. Podem ter caráter permanente ou esporádico.

7 Aqui considerados a participação em projetos de extensão, em eventos acadêmicos, no programa integrado de bolsas da UFES, a publicação de artigos, participação em pesquisas e em projetos desenvolvidos no interior das disciplinas curriculares, seminários de estudos e/ou oficinas. No Projeto Curricular do CEFD/UFES há uma pontuação que converte e contabiliza tais experiências em carga horária.

8 Por uma questão de espaço, o ementário das disciplinas não pode ser aqui apresentado. Ele está disponível no Projeto Curricular do curso de licenciatura em Educação Física do CEFD/UFES.

9 Na proposta inicial essa disciplina chamava-se Sujeitos em Processo de Escolarização.

\section{REFERÊNCIAS}

DEMO, P. Educar pela pesquisa. Campinas: Autores Associados, 1997.

FAZENDA, I. Integração e interdisciplinaridade no ensino brasileiro: efetividade ou ideologia. São Paulo: Loyola, 1993. 
FIGUEIREDO, Z. C. C. Experiências sociais no processo de formação docente em Educação Física. 2003. 210 f. Tese (Doutorado em Educação) - Programa de Pós-graduação em Educação da Faculdade de Educação, Universidade Federal de Minas Gerais, Belo Horizonte, 2003

NUNES, C. M. F. Saberes docentes e formação de professores: um breve panorama da pesquisa brasileira. Educação e Sociedade, Campinas, ano 22, v. 74, p. 27-42, abr. 2001.

NÓVOA, A. (Coord.) Os professores e a sua formação. Portugal: Publicações Dom Quixote, 1997.

PIMENTA, S. G. Formação de professores: identidade e saberes da docência. In: . (Org.). Saberes pedagógicos e atividade docente. São Paulo: Cortez, 2000. p. 15-34.

SACRISTÁN, J. G. O currículo: uma reflexão sobre a prática. 3. ed. Porto Alegre: Artmed, 2000.

SILVA, D. M. C. da. A história da Escola de Educação Física do Espírito Santo (1930-1945). 1991. 71 f. Monografia (Pós-graduação Lato Sensu em Educação Física Escolar) - Centro de Educação Física e Desportos, Universidade Federal do Espírito Santo, Vitória, 1991.

VEIGA NETO, A. Currículo, disciplina e interdisciplinaridade. Revista Brasileira de Ciências do Esporte, Campinas, v. 17, n. 2, p. 128-137, jan. 1996.

Recebido: 31 de março de 2006

Aprovado: 10 de abril de 2006

Endereço para correspondência:

CEFD/UFES

Av. Fernando Ferrari, 514, Campus Universitário

Goiabeiras - Vitória - Espírito Santo

CEP 29075-910

E-mail: feepaiva@hotmail.com 